\title{
A OUVIDORIA PÚBLICA COMO PROTETORA DE DIREITOS
}

\author{
Vilson Pedro Nery ${ }^{1}$
}

\section{Resumo}

No processo de elaboração da Constituição Federal de 1988, um debate intenso foi travado entre duas forças sociais e políticas, o confronto deu-se entre aqueles que defendiam a consolidação das atribuições do Ministério Público como elo entre o cidadão e a Administração e outros agentes, que preferiam que as funções de Ombudsman fossem afetadas às Ouvidorias. Após três décadas da edição da Carta Cidadã, as inovações normativas empoderam as Ouvidorias e ao mesmo tempo Ihes atribuem mais encargos. A Lei $n^{\circ} 13.460 / 2017$, que instituiu o Código de Defesa do Usuário de Serviços Públicos, dedica dois capítulos às Ouvidorias, dispondo que elas devem acompanhar a prestação de serviços, garantindo sua efetividade, e prevê que a Ouvidoria pode fazer a conciliação e mediação de conflitos existentes entre o usuário e a Administração (art. 13, VII). No Estado de Mato Grosso, as Ouvidorias do Poder Executivo funcionam em rede, sendo que as Ouvidorias Setoriais e as Especializadas são vinculadas operacionalmente à Ouvidoria-Geral do Estado (OGE), hoje coordenada pela Controladoria-Geral do Estado (CGE), como uma das quatro macrofunções de controle. Ao centralizar a recepção e as demandas, a OGE disciplina e regulamenta a prestação desse serviço e caminha a passos largos no sentido de disciplinar a mediação e a solução de conflitos, cujo planejamento ainda se encontra na fase preliminar. Atuando como Ombudsman ou Defensor del Pueblo, conforme os modelos consagrados, a Ouvidoria Pública pode ser uma garantidora de direitos do cidadão.

Palavras-chave: Ouvidoria. Direitos. Garantia.

DOI:10.37814/2594-5068.2020v3.p183-190

1 Vilson Pedro Nery, Advogado e Auditor do Estado na Controladoria-Geral do Estado de Mato Grosso (CGE/MT), Superintendente de Ouvidoria, exercendo as atribuições de Ouvidor-Geral, é Mestre em Educação pela UFMT. (vilsonery@gmail.com) (vilsonnery@controladoria.mt.gov.br) 


\begin{abstract}
In the process of elaborating the Federal Constitution of 1988, an intense debate was fought between two social and political forces, the confrontation took place between those who defended the consolidation of the attributions of the Public Ministry as a link between the citizen and the Administration and other agents, who preferred that Ombudsman duties be assigned to Ombudsman's offices. After three decades since the edition of the Citizen Charter, normative innovations empower the Ombudsman's offices and at the same time place more burdens on them. Law n. 13.460/2017, which established the Public Services Users Code, devotes two chapters to the Ombudsman's offices, providing that they must monitor the provision of services, ensuring their effectiveness, and even provides that the Ombudsman can conciliate and mediate conflicts between the user and the Administration (article 13, VII). In the State of Mato Grosso, the Ombudsman's office of the Executive Branch operate in a network, and all the Ombudsmen and specialized Ombudsmen are operationally linked to the State Ombudsman Office (OGE), now coordinated by the State Comptroller General (CGE), as one of the four control macrofunctions. By centralizing the reception and demands, the OGE disciplines and regulates the provision of this service and is striding in the direction of disciplining mediation and conflict resolution, whose planning is still in the preliminary phase. Acting as Ombudsman or Defender of the People, according to the established models, the public Ombudsman can be a guarantor of citizen's rights.
\end{abstract}

Keywords: Ombudsman. Rights. Warranty. 


\section{INTRODUÇÃO}

De acordo com a tradição republicana, a representação do cidadão perante a Administração Pública pode ocorrer de diversas formas, ele mesmo podendo reclamar atendimento e adequada prestação de serviços pessoalmente, sem mediação. Naquelas situações em que o direito de uma coletividade deixa de ser observado pelo ente estatal, o Ministério Público possui instrumentos processuais legítimos para dar concretude ao controle externo da Administração, atuando na defesa dos interesses e direitos individuais e coletivos.

O presente artigo tem por objetivo demonstrar a configuração do sistema de Ouvidorias Públicas existentes no âmbito do Poder Executivo do Estado de Mato Grosso, cujo serviço foi instituído por meio da Lei Complementar n 162/2004 e aperfeiçoado alguns anos depois, quando a Controladoria-Geral do Estado (CGE/MT) assume a macrofunção de Ouvidoria em seu feixe de atribuições, conforme a Lei Complementar n 550/2014.

Nos dias atuais, a cidadania pode contar com as Ouvidorias Públicas como sendo mais um instrumento na proteção de seus direitos, que pode auxiliar o controle social na vigilância e controle da prestação de serviços públicos.

Em Mato Grosso, a lei instituidora das Ouvidorias Públicas criou diversas atribuições, possibilitando o exercício da mediação dos conflitos que chegam ao seu conhecimento, tornando a Ouvidoria um importante instrumento de cidadania, na proteção, promoção e garantia de direitos.

De acordo com as normas locais, é possível às Ouvidorias Públicas a assunção do protagonismo na defesa de direitos e garantias da população, dando sugestões sobre a propositura de políticas públicas aos gestores e contribuindo com a correição dos atos que sejam maléficos à sociedade, nesse caso colaborando com o controle preventivo dos serviços e das políticas públicas, sob a ótica dos usuários do serviço público, conciliando e mediando as controvérsias. A possibilidade de mediar os conflitos reais é a grande novidade trazida pela norma federal recente, e isso pode representar a adoção de um novo padrão na solução de conflitos.

Constata-se que a norma contida na Lei de Acesso à Informação, bem como na Lei federal $\mathrm{n}^{\circ}$ 13.460/2017, aquela que dispôs sobre a participação, proteção e defesa dos direitos do usuário dos serviços públicos, instituindo o Código de Defesa dos Usuários dos serviços públicos, é recepcionada pelas normas locais. A LAI foi regulamentada por meio do Decreto Estadual n 1973/2013, e a aplicação do Código dos Usuários dos serviços públicos está prevista em minuta de Decreto pendente de publicação em Diário Oficial. Em Mato Grosso, desde o ano de 2004, existe a possibilidade de que a Ouvidoria atue diretamente nas proposições de políticas públicas, com base nas informações existentes sobre as reiterações de problemas e nas chamadas matrizes de risco (identificação de problemas recorrentes, graças às denúncias e reclamações recepcionadas pelas Ouvidorias Públicas).

Um dos mais dedicados estudiosos dos sistemas de Ouvidorias no Brasil, o professor Rubens Pinto Lyra, jurista que possui vasta pesquisa e inúmeras obras escritas sobre o tema, narra um conflito que existiu no processo de elaboração da Constituinte de 1988, quando os defensores de instituições como Ouvidorias e o Ministério Público "disputaram" espaços dentro do texto constitucional. 
Há um relato no artigo "Ministério Público e Ouvidorias: as duas faces do Ombudsman no Brasil", em que o professor Lyra retrata que

No Brasil, duas instituições compartilharam as prerrogativas do Ombudsman e dos seus similares: o Ministério Público e as Ouvidorias. Contudo, já se tornou tradição, em nosso país, associar as primeiras às oficinas de Ombudsman, em que pese a existência, entre estas, do lado de notórias semelhanças, de diferenças significativas. (LYRA, 2014, p. 97)

O artigo acima referenciado trata da relação entre as atribuições e competências dos diversos órgãos com perfil para exercer as funções de Ombudsman, fiscal do povo, ou Defensor del Pueblo, e cita a legitimidade processual do Ministério Público para a proposituras de diversas demandas judiciais de natureza coletiva, como os inquéritos civis, as ações civis públicas e os Termos de Ajustamento de Conduta. Há que se observar que as competências para "estar em Juízo" não foram estendidas às Ouvidorias Públicas, embora na atualidade as configurações dessas instituições permitam a atuação nos casos concretos (fazendo a mediação) ou mesmo atender a sociedade coletivamente, apresentando sugestões de políticas públicas no sentido de solucionar demandas sociais (controle preventivo).

Isso vai bem além da já consagrada expertise para mediar os conflitos travados pelo cidadão com os órgãos da Administração Pública, porque um sistema de Ouvidorias pode sugerir adoção de políticas com base no conjunto das reclamações e denúncias recebidas e tratadas.

Neste artigo pretendemos identificar os marcos regulatórios relativos às Ouvidorias Públicas, consultar a bibliografia científica existente sobre o tema e, por fim, demonstrar que a Administração Pública deve disponibilizar esse valioso instrumento a serviço da população como mais uma ferramenta que representa uma garantia ao exercício de direitos.

À guisa de esclarecimento, a locução "Ministério Público" é apresentada 82 vezes no texto da Constituição Federal, e a palavra "Ouvidoria" é citada em duas oportunidades, uma delas, inclusive, dispõe sobre a criação desse serviço no Ministério Público (art. 130, $\S 5^{\circ}$ ). De acordo com a intenção do legislador constituinte, "O Ministério Público é instituição permanente, essencial à função jurisdicional do Estado, incumbindo-Ihe a defesa da ordem jurídica, do regime democrático e dos interesses sociais e individuais indisponíveis" (art. 127).

Portanto, analisando as normas locais citadas em nossa investigação, é possível interpretar que a Ouvidoria Pública é "defensora do regime democrático" e "garante a proteção dos interesses coletivos e individuais", quase fazendo uma intersecção com os poderes do Ministério Público.

\section{DESENVOLVIMENTO}

Para realizar este estudo buscamos inspiração nas doutrinas existentes sobre o tema de Ouvidorias Públicas e os marcos legais no plano federal e local sobre este importante serviço posto à disposição do público. Nossa intenção é apresentar o modelo de Ouvidorias Públicas adotado pelo Poder Executivo do Estado de Mato Grosso, apresentando as competências e atribuições concedidas por lei e os desafios que se avizinham com a regulamentação das normas federais. Assim, a 
maior parte do artigo se baseia no conjunto das normas legais que regem o serviço, sempre considerando que as Ouvidorias mato-grossenses operam em rede, com a Controladoria-Geral do Estado (CGE) organizando e disciplinando a atuação das Ouvidorias Setoriais e das Especializadas, no cumprimento da macrofunção de Ouvidoria.

Para complementar as informações, vamos fazer rápida comparação com os sistemas já existentes em países europeus, com base na investigação bibliográfica, consultando o acervo já produzido sobre Ouvidorias e Ombudsman.

As competências relativas às atividades de Ouvidoria no âmbito do Poder Executivo de Mato Grosso são exercidas pela Controladoria-Geral do Estado nos termos da Lei Complementar $n^{\circ}$ 550/2014 (art. $3^{\circ}$ ). Bem antes, a norma estadual que criou o sistema de Ouvidorias, a LC 162/04, já tratava das competências:

Art. $2^{\circ}$ Compete à Ouvidoria-Geral do Estado:

I - atuar na defesa dos direitos e interesses individuais e coletivos;

II - tomar iniciativas para correção de atos e omissões, ilegais ou injustos, cometidos no âmbito do Poder Executivo Estadual;

III - receber reclamações ou denúncias que lhe forem dirigidas e encaminhá-las para a solução aos órgãos competentes, para as providências cabíveis;

IV - recomendar medidas para a correção de atos contrários à lei ou regras da boa administração, representando, quando necessário, aos órgãos e entidades competentes;

$\mathrm{V}$ - garantir, a todos quantos procurarem a Ouvidoria, o retorno das providências adotadas a partir de sua intervenção e dos resultados alcançados;

$\mathrm{VI}$ - garantir a todos os demandantes um caráter de discrição e de fidelidade ao que the for transmitido;

VII - sugerir medidas de aprimoramento da prestação de serviços administrativos com base nas reclamações, denúncias e sugestões recebidas, visando garantir que os problemas detectados não se tornem objeto de repetições contínuas;

VIII - divulgar, permanentemente, os serviços da Ouvidoria-Geral do Estado ao público, para conhecimento, utilização continuada e ciência dos resultados alcançados;

IX - promover a realização de pesquisa, seminários e cursos sobre assuntos relativos ao exercício dos direitos e deveres do cidadão perante a Administração Pública;

$\mathrm{X}$ - organizar e manter atualizado arquivo da documentação relativa às denúncias, queixas, reclamações e sugestões recebidas;

$\mathrm{XI}$ - desenvolver outras atividades correlatas.

É forçoso notar que a possibilidade de fazer a mediação de conflitos entre o cidadão usuário de serviço público e a Administração, na forma dos Capítulos III e IV da Lei federal n 13.460/2017, no sentido de buscar uma conciliação, já encontrava permissão no âmbito regional desde o ano de 2004.

Percebe-se que o sistema de Ouvidorias Públicas não se contenta somente em receber a demanda do usuário externo, uma reclamação, denúncia ou pedido de informação, pois é possível tomar a iniciativa da correção de atos ilegais ou injustos e ainda recomendar a correção de atos contrários às regras da boa administração. Tudo de acordo com o perfil que se espera de um Ombudsman ou fiscal da lei.

Na coletânea A Ouvidoria Pública no Brasil: modelos em disputa, organizada pelo professor doutor Rubens Pinto Lyra, o conceito de "Ombudsman" é apresentado pelo Ouvidor do Tribunal 
Regional Federal da $4^{\mathrm{a}}$ Região, o desembargador federal Ricardo Teixeira do Valle Pereira,

Há uma grande variedade de nomes utilizados para denominar a figura do Ombudsman. Podem ser mencionadas como exemplos as seguintes denominações: Defensor del Pueblo, em muitos países de língua espanhola, como Espanha, Argentina, Peru e Colômbia; Parliamentary Commissioner for Administration, no Reino Unido; Médiateur de la République, na França; Public Protector, na África do Sul; Protecteur du Citoyen, na província de Quebec; Wolksanwaltschaft, na Áustria; Public Complaints Commission, na Nigéria; Provedor de Justiça, em Portugal; Difensore Civico, na Itália; Procurador de los Derechos Humanos, na Guatemala; Procurador para la Defensa de los Derechos Humanos, em El Salvador; Comisión Nacional de Derechos Humanos, no México. As atribuições do Ombudsman variam de país para país, haja vistas as particularidades dos respectivos ordenamentos jurídicos. (LYRA (Org.), 2014, p. 239-240)

A citação acima mostra que, no Direito comparado, a semelhança das atribuições da Ouvidoria e do Ministério Público não se trata de uma criação tipicamente brasileira, ainda que a instituição do Parquet tenha ganhado mais força e musculatura na elaboração da Constituição Federal de 1988. Ocorre que na realidade brasileira a utilização do Poder Judiciário para a solução pacífica de conflitos implica demorados processos judiciais, em regra a solução é quase sempre tardia e nem sempre agrada ao demandante. Desse modo, o meio que o Ministério Público dispõe para a sua atuação é eficiente e eficaz, mas nem sempre célere.

Já as organizações administrativas públicas, e aqui se acentua o papel das Ouvidorias do setor público, podem dar a mesma solução ao cidadão em menor tempo, sem entrar em choque de atribuições com o Ministério Público. Ao exercer as atribuições de mediação entre o usuário do serviço público e a Administração, a Ouvidoria pode dar uma solução com muito mais precisão, com rapidez e eficiência, o que evidencia sua face de garantidora de direitos.

Quando falamos em "direito" nos referimos ao direito material, uma prestação positiva que o cidadão pode obter do Estado, ou mesmo em relação a terceiros. Já a "garantia" é a forma de exercício desse direito, o processo de busca da concretização, o iter ou processo.

Veja-se o exemplo de cidadão que precisa saber o teor de uma informação sobre si que está nos sistemas e bancos de dados oficiais, para o exercício futuro de um direito ou com o mero propósito de retificação. Ele pode fazer uso de um habeas data, remédio processual que garante a fiscalização do Ministério Público (Lei n 9.507/97, art. 12), ou pode acionar a Ouvidoria Pública do Poder Executivo, caso em que a resposta pela via administrativa poderia ser bem mais rápida, vide os prazos da LAI e do Código do Usuário dos serviços públicos. É inegável o perfil das Ouvidorias como garantidoras de direitos, um meio eficaz para a concretude das aspirações cidadãs.

\section{CONSIDERAÇÕES}

Num momento em que a população sofre com a restrição de direitos, entendemos que as Ouvidorias Públicas podem exercer um protagonismo dentro do sistema de proteção de direitos e garantias no Brasil. Graças às experiências já existentes nos sistemas de Ouvidorias Públicas em seus diversos modelos, é possível admitir que, além do Ministério Público, também a Ouvidoria 
Pública pode atuar na defesa dos interesses e direitos coletivos. Ainda que a Constituição Federal de 1988 originalmente tenha ofertado pouco espaço para as Ouvidorias Públicas, na prática rotineira da Administração as Ouvidorias acabam por exercer um papel relevante na fiscalização, controle e proposição de políticas. A escassez de espaço na versão original da Carta Magna foi combatida com a edição da Emenda 19/98, que previu a necessidade da edição de uma lei para disciplinar as formas de participação do usuário na Administração Pública (Cf, art. 37, § $3^{\circ}$ ). Ainda que haja controvérsia, entendemos que não existe um modelo único de Ouvidoria Pública no Brasil (ainda que a Lei 13.460/2017 preveja parâmetros mínimos), mas as experiências de entes diversos, como evidenciado neste artigo e em obras consagradas, demonstram que a atuação de um Ombudsman ou Defensor del Pueblo é perfeitamente compatível com a ordem jurídica nacional.

No Estado de Mato Grosso existe uma Ouvidoria-Geral que recebe as demandas dos cidadãos - denúncias, reclamações e pedidos de acesso à informação - e as distribui às chamadas Ouvidorias Setoriais ou Especializadas. São elas, sob orientação técnica do órgão central, mas conhecedoras do ambiente de negócios da entidade setorizada (secretaria, autarquia, empresa pública, sociedade de economia mista ou fundação), que buscam na origem a informação que atende às demandas da população.

Naquelas situações em que há a reiteração de pedidos semelhantes, a própria Ouvidoria-Geral pode sugerir a adoção de políticas públicas, com o propósito de solucionar eventual falha verificada na atuação da Administração Pública.

O ideal é que a própria Administração, através de uma de suas estruturas, a Ouvidoria, possa ser a "caixa de ressonância" dos anseios da população e o órgão capacitado para mediar o conflito no caso concreto, contando ainda com capacidade técnica de propor soluções adequadas aos problemas identificados na rotina da Administração.

É possível crer que já existem bases jurídicas que permitem que a Ouvidoria Pública seja mais um instrumento posto à disposição da população para a garantia e o exercício de direitos constitucionalmente previstos. Sabe-se que a forma de participação direta do cidadão na rotina da Administração, criação do art. $37, \S 3^{\circ}$ da Carta Magna e detalhada por meio da Lei federal $n^{\circ}$ 13.460/2017, significa que a Ouvidoria Pública é um canal posto à disposição da defesa de direitos dos usuários dos serviços públicos. A Ouvidoria é uma garantidora do exercício de direitos, cujos efeitos de sua atuação se assemelham a um habeas data ou mandado de segurança, mutatis mutandis, e que precisa ser mais bem explorada.

\section{REFERÊNCIAS}

BRASIL. Constituição (1988). Constituição da República Federativa do Brasil. Brasília, DF: Senado, 1988.

Lei Complementar n 162, de 29 de março de 2004. Cria a Ouvidoria-Geral de Mato Grosso.

. Lei Complementar n 550, de 27 de novembro de 2014. Transforma a Auditoria-Geral do Estado em Controladoria-Geral do Estado, dá novas atribuições e outras providências.

Lei n 12.527, de 18 de novembro de 2011: Lei de Acesso à Informação. 

Lei $n^{\circ} 13.460$, de 26 de junho de 2017.

MARTINS JÚNIOR, Wallace Paiva. Transparência administrativa: publicidade, motivação e participação popular. São Paulo: Editora Saraiva, 2004.

LYRA, Pinto (Org). A Ouvidoria Pública no Brasil: modelos em disputa. João Pessoa: Editora da UFPB, 2014.

ZYMLER, Benjamin. Direito Administrativo e Controle, Belo Horizonte: Fórum, 2015. 